\title{
PELATIHAN PIJAT OKSITOSIN BAGI PENDAMPING IBU NIFAS
}

\author{
Sumiaty*, Muliani, Lisnawati \\ ${ }^{1}$ Jurusan Kebidanan Poltekkes Kemenkes Palu \\ *email korespondensi: sumiatyakbid@gmail.com
}

\begin{abstract}
Inadequate milk production in the first days after delivery is caused by a lack of stimulation of the hormone prolactin and the hormone oxytocin. Decreasing milk production is caused by decreased stimulation of hormones prolactin and oxytocin. Efforts that can be made to stimulate the increase of hormone prolactin and oxytocin, including initiating early breastfeeding, expressing breast milk, and doing oxytocin massage, are practical and efficient in increasing milk production. Data from the Public Health Office of Palu in 2017 and 2018 showed that the average of exclusive breastfeeding coverage in 11 sub-districts in Central Sulawesi Province is $<50 \%$ and specifically Kota Palu exclusive breastfeeding coverage only $49.6 \%$ in 2017 and then dropped to $49,3 \%$ in 2018 . Oxytocin massage training has never been conducted at the Tawaeli Community Health Center, especially for postpartum mothers companions such as Posyandu Cadres, Husbands, or Families. The method used in community service activities was discussions, simulations, and demonstrations using leaflet and audiovisual media. The number of puerperal mothers who attended the training was 25 people. The results of training activities for postpartum mothers in the Kayumalue Ngapa village obtained that the results of knowledge analysis overall increased in the knowledge of 25 participants after attending the training, with an average increase of 13 points. The $\mathrm{p}$-value $<0,001$ results meant that statistically, there was a significant effect on the increase of knowledge of postpartum mothers companion after attending oxytocin massage training. To sum up that there is a significant increase in knowledge between before and after training on oxytocin massage in stimulating milk production. It is recommended that health workers need to be consistent and continuous in giving training to the companion of the postpartum mother (husband, family or cadre) in order to be able to assist the process of changing behavior for the postpartum mother to provide exclusive breastfeeding and conduct care during the postpartum period.
\end{abstract}

Keywords: Training, Oxytocin Massage, Companion of the postpartum mother

\begin{abstract}
ABSTRAK
Produksi ASI yang kurang pada hari-hari pertama setelah melahirkan disebabkan oleh kurangnya rangsangan hormon prolaktin dan hormon oksitosin. Penurunan produksi ASI disebabkan karena menurunnya stimulasi hormon prolaktin dan oksitosin. Upaya-upaya yang dapat dilakukan untuk merangsang peningkatan hormon prolaktin dan oksitosin antara lain melakukan inisiasi menyusu dini, memeras ASI dan melakukan pijat oksitosin sedangkan perawatan payudara (breast care) pada ibu post partum kurang efektif dan efisien terhadap peningkatan produksi ASI. Data dinas kesehatan Kota Palu pada tahun 2017 dan 2018 menunjukkan bahwa rata-rata cakupan ASI Eksklusif pada 11 Kabupaten di Propinsi Sulawesi Tengah adalah $<50 \%$ dan khusus Kota Palu cakupan ASI eksklusif hanya 49,6\% pada tahun 2017 dan kemudian turun menjadi 49,3\% pada tahun 2018. Pelatihan pijat oksitosin belum pernah dilakukan di Puskesmas Tawaeli, khususnya kepada para pendamping ASI seperti para Kader Posyandu, Para Suami atau Keluarga. Metode yang digunakan pada kegiatan pengabdian pada masyarakat ini adalah metode ceramah, diskusi, simulasi dan demonstrasi menggunakan media leaflet dan audio visual. Jumlah Pendamping Ibu nifas yang mengikuti pelatihan sebanyak 25 orang. Hasil kegiatan pelatihan pada pendamping ibu nifas di kelurahan Kayumalue Ngapa diperoleh bahwa hasil analisis pengetahuan menunjukan bahwa secara keseluruhan terjadi peningkatan pengetahuan pada 25 orang peserta setelah mengikuti pelatihan, dengan rata-rata peningkatan sebesar 13 poin. Hasil p-value $<0.001$ artinya bahwa secara statistik terdapat pengaruh yang signifikan terhadap peningkatan pengetahuan para pendamping ibu nifas sesudah mengikuti pelatihan pijat oksitosin. Maka disimpulkan ada peningkatan pengetahuan yang signifikan antara
\end{abstract}


sebelum dan sesudah pelatihan tentang pijat oksitosin. Disarankan agar petugas kesehatan perlu konsisten dan berkelanjutan memberikan pelatihan kepada para pendamping ibu nifas (suami, keluarga atau kader) agar dapat membantu proses perubahan perilaku pada ibu nifas untuk memberikan ASI secara Eksklusif dan melakukan perawatan selama masa nifas.

\section{Kata Kunci: Pelatihan, Pijat Oksitosin, Pendamping Ibu Nifas.}

\section{PENDAHULUAN}

Air susu ibu (ASI) merupakan makanan alami yang paling ideal dan terbaik untuk bayi, berkomposisi seimbang, dan secara alami disesuaikan dengan masa pertumbuhan bayi. Air susu ibu adalah makanan bayi yang paling sempurna baik kualitas maupun kuantitasnya, oleh karena itu sejak tahun 1992 World Health Organization (WHO) telah mencanangkan dan mempromosikan penggunaan air susu ibu ke seluruh dunia sebagai upaya dalam meningkatan derajat kesehatan umat manusia sedunia (WHO \& FAO, 2002).

Faktor-faktor yang mempengaruhi rendahnya pemberian ASI antara lain ASI tidak segera keluar setelah melahirkan, produksi ASI kurang, kesulitan bayi dalam mengisap, keadaan puting susu ibu, pengaruh promosi pengganti ASI dan kurangnya dukungan ditempat kerja pada ibu yang menyusui (Siregar, 2004). Penelitian Colin dan Scott tahun 2002 di Australia juga menunjukkan bahwa $29 \%$ ibu post partum berhenti menyusui karena produksi ASI berkurang.

Menurut Cox (2006) disebutkan bahwa ibu yang tidak menyusui bayinya pada hari-hari pertama menyusui disebabkan oleh kecemasan dan ketakutan ibu akan kurangnya produksi ASI serta kurangnya pengetahuan ibu tentang proses menyusui. Akan tetapi beberapa penelitian ini berbeda dengan hasil penelitian Roesli (2005) yang membuktikan bahwa tidak ada ibu yang kekurangan produksi ASI.

Produksi ASI yang kurang pada hari-hari pertama setelah melahirkan disebabkan oleh kurangnya rangsangan hormon prolaktin dan hormon oksitosin. Hal ini sesuai dengan penelitian yang dilakukan oleh Pace (2001) yang menunjukkan bahwa penurunan produksi ASI disebabkan karena menurunnya stimulasi hormon prolaktin dan oksitosin.

Upaya-upaya yang dapat dilakukan untuk merangsang peningkatan hormon prolaktin dan oksitosin antara lain melakukan inisiasi menyusu dini, memeras ASI dan melakukan pijat oksitosin sedangkan perawatan payudara (breast care) pada ibu post partum kurang efektif dan efisien terhadap peningkatan produksi ASI (Roesli \& Yolmi, 2009). Penelitian Desmawati (2008) tentang efektifitas kombinasi aerolla massage dan rolling massage terhadap pengeluaran ASI secara dini pada ibu post partum di Puskesmas Pamulang dan Cikupa Banten menunjukkan bahwa ibu-ibu yang diberikan intervensi tersebut memiliki peluang 5,146 kali untuk terjadinya pengeluaran ASI dalam waktu 12 jam post partum.

Bila meninjau data profil Dinas Kesehatan Propinsi Sulawesi Tengah tahun 2017 dan 2018 menunjukkan bahwa rata-rata cakupan ASI Eksklusif pada 11 Kabupaten di Propinsi Sulawesi Tengah adalah $<50 \%$ dan khusus Kota Palu cakupan ASI eksklusif hanya 49,6\% pada tahun 2017 dan kemudian turun menjadi 49,3\% pada tahun 2018.

Pelatihan pijat oksitosin pada pendamping ibu nifas (Suami, keluarga atau Kader) dilaksanakan dengan menggunakan teknik pelatihan metode pembelajaran orang dewasa, memanfaatkan ruangan yang ada, yaitu ruang pertemuan puskesmas Tawaeli, posyandu ataupun di rumah ibu nifas. Selain masalah cakupan ASI eksklusif, alasan lain dilaksanakannya kegiatan pengabdian masyarakat di Kelurahan Kayumalue Ngapa oleh karena daerah ini merupakan daerah lokus pembinaan dari Badan Nasional Penanggulangan Terorisme (BNPT). 


\section{METODE PELAKSANAAN}

Tempat dan Waktu. Pengabdian masyarakat bertempat di Kelurahan Kayumalue Ngapa pada tanggal 19 Agustus sampai dengan 18 Oktober 2019. Pelatihan awal dilaksanakan selama 2 hari pada tanggal 26-27 Agustus 2019 di ruang pertemuan Puskesmas Tawaeli dan selanjutnya dilakukan follow up pasca pelatihan sampai tanggal 18 oktober 2019 di rumah ibu nifas.

Khalayak Sasaran. Sasaran kegiatan adalah 25 orang pendamping ibu nifas yang ada di Kelurahan Kayumalue Ngapa, terdiri dari suami, keluarga dan kader. Namun pada pelaksanaan kegiatan yang hadir hanyalah keluarga ibu nifas (13 orang) dan kader (12 orang). Sedangkan suami tidak hadir pada pelatihan awal dikarenakan sibuk bekerja.

Metode Pengabdian. Metode pengabdian masyarakat berupa diskusi, simulasi dan demontrasi. Fasilitator dalam pelatihan ini adalah Sumiaty, SST. MPH, Muliani, S.Kep.Ns., M.Sc dan Lisnawati, S.Kep.Ns. MPH. Materi pelatihan meliputi ASI Eksklusif, Upayaupaya meningkatkan produksi ASI secara metode farmakologi dan non farmakologi, cara menstimulasi Produksi ASI, serta Teknik Pijat Oksitosin.

Indikator Keberhasilan. Indikator keberkasilan pelatihan ini adalah peningkatan pengetahuan para pendamping ibu nifas mengenai praktik pijat oksitosin dan mampu melakukan teknik pijat oksitosin pada ibu nifas.

Metode Evaluasi. Metode evaluasi pre dan post test serta daftar tilik pijat oksitosin.

\section{HASIL DAN PEMBAHASAN}

\section{A. Hasil.}

Pelatihan awal dilaksanakan selama 2 hari pada tanggal 26-27 Agustus 2019 di ruang pertemuan Puskesmas Tawaeli di mulai pukul 09.00 Wita dan berakhir di jam 13.00 dengan melibatkan peserta sebanyak 25 orang. Peserta kader berasal dari 4 posyandu yang ada di kayumalue ngapa yaitu Posyandu Kenanga, Kemuning, Tulip dan Kamboja, dengan masing-masing diwakili 3 orang/Posyandu. Pembukaan kegiatan pelatihan dihadiri oleh Kepala Puskesmas Tawaeli, bidan poskesdes, ibu nifas dan para pendamping ibu nifas.

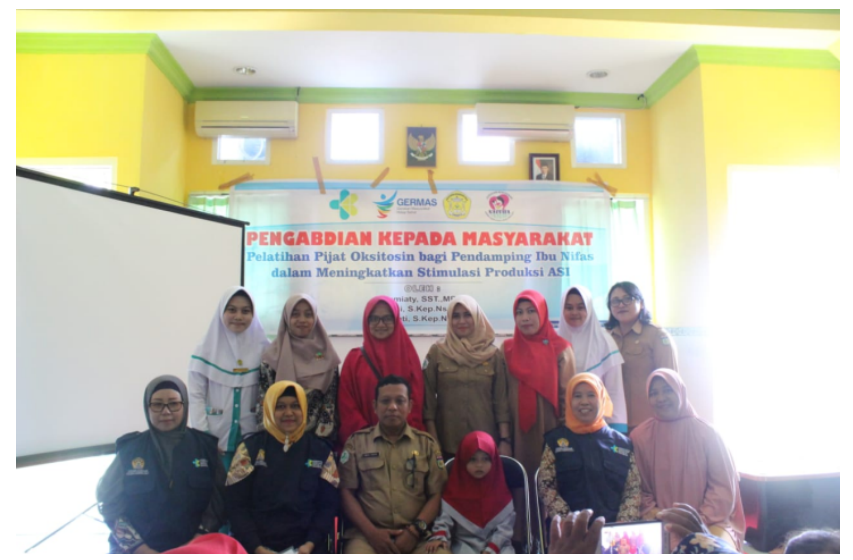

Gambar 1. Foto bersama Kepala Puskesmas Tawaeli, Bidan Poskesdes dan Mahasiswa

Peserta pengabdian masyarakat ini berlatar pendidikan SMA. Sebagian besar peserta bekerja sebagai ibu rumah tangga, pedagang, dan guru di sekolah dasar. Materi dalam pelatihan ini meliputi ASI Eksklusif, Upaya-upaya meningkatkan produksi ASI secara metode farmakologi dan non farmakologi, cara menstimulasi Produksi ASI, serta Teknik Pijat Oksitosin. 


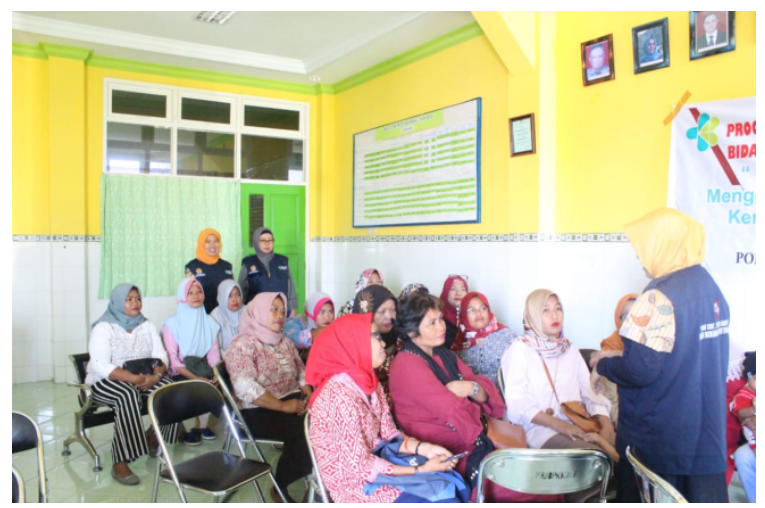

Gambar 2. Foto Pemberian Materi Pelatihan dan Diskusi dengan para peserta

Pada kegiatan ini dilakukan pengukuran tingkat pengetahuan melalui kegiatan pre dan post test dengan jumlah soal sebanyak 10 item pertanyaan. Dari hasil penilaian tingkat pengetahuan melalui pre dan post test yang dilakukan diperoleh hasil sebagai berikut:

Tabel. 1 Hasil analisis uji Wilcoxon terhadap tingkat pengetahuan hasil Pre dan Postest

\begin{tabular}{|c|c|c|c|c|}
\hline \multirow{2}{*}{ Pengetahuan } & Median & \multicolumn{2}{|c|}{$\mathrm{N}($ mean rank $)$} & Nilai \\
& $($ Min-Mak $)$ & $(-)$ rank & $(+)$ rank & p-value \\
\hline Pengetahuan sebelum penyuluhan $(\mathrm{n}=25)$ & $6(4-12)$ & \multirow{2}{*}{$0(0.00)$} & $25(13.00)$ & $<0,001$ \\
\hline Pengetahuan sesudah penyuluhan $(\mathrm{n}=25)$ & $14(12-14)$ & & \\
\hline
\end{tabular}

Uji Wilcoxon, tidak ada nilai yang sama $($ ties $=0)$

Berdasarkan tabel 1. hasil analisis uji wilcoxon terhadap tingkat pengetahuan sebelum dan sesudah penyuluhan menunjukan bahwa secara keseluruhan terjadi peningkatan pengetahuan pada 25 orang peserta setelah mengikuti pelatihan, dengan ratarata peningkatan sebesar 13. Berdasarkan hasil uji wilxocon diperoleh hasil $p$-value $<0,005$ (p-value $<0.001$ ), hal ini menunjukkan bahwa secara statistik terdapat pengaruh pelatihan pijat oksitosin terhadap peningkatan pengetahuan para pendamping ibu nifas. Para pendamping ibu nifas memahami bahwa salah satu teknik menstimulasi produksi ASI yang dapat digunakan adalah pijat oksitosin.

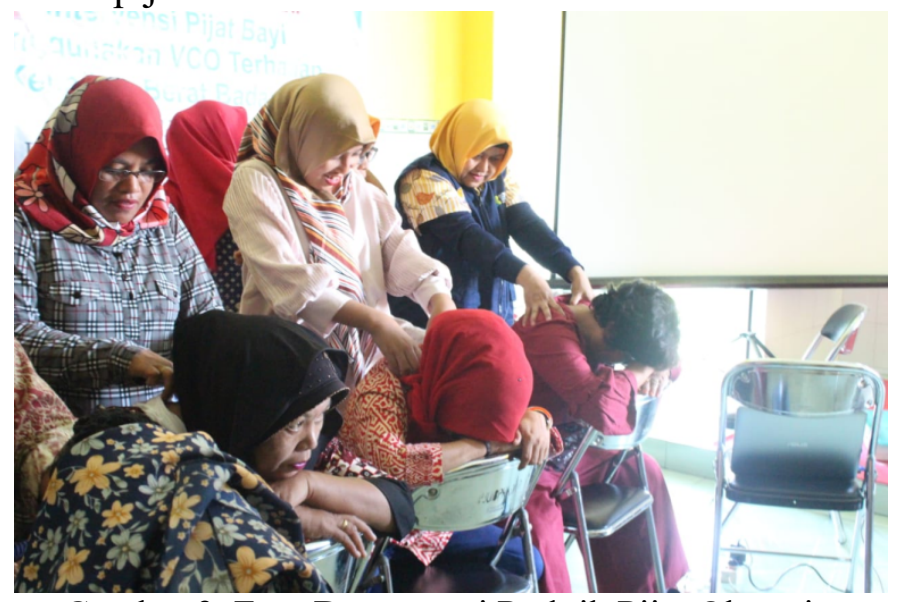

Gambar 3. Foto Demostrasi Praktik Pijat Okstosin

Maka rencana tidak lanjut kegiatan pengabdian masyarakat ini adalah para pendamping ibu nifas akan memotivasi ibu nifas untuk memberikan ASI eksklusif secara paripurna tanpa khawatir akan ASI yang kurang. Para pendamping ibu nifas akan membantu ibu nifas yang mengalami kesulitan menyusui dengan melakukan edukasi tentang ASI Eksklusif dan pijat oksitosin. 


\section{B. Pembahasan.}

Kegagalan dalam proses menyusui sering disebabkan karena timbulnya beberapa masalah, baik masalah pada ibu maupun pada bayi. Masalah dari ibu yang timbul selama menyusui dapat dimulai sejak sebelum persalinan (periode antenatal), pada masa persalinan dini dan masa pasca persalinan lanjut. Ibu sering mengeluh bahwa bayinya sering menangis atau menolak menyusu, yang sering diartikan bahwa ASI nya tidak cukup atau ASI nya tidak enak, tidak baik sehingga menyebabkan ibu mengambil keputusan untuk berhenti menyusui (Suradi dan Tobing, 2004).

Pijat oksitosin merupakan salah satu intervensi secara non farmakologi menstimulasi produksi ASI, yang dapat dilakukan oleh para pendamping ibu nifas dalam membantu proses ibu untuk menyusui. Pijat oksitosin adalah pemijatan tulang belakang pada nervus kelima atau keenam sampai kescapula yang akan mempercepat kerja saraf parasimpatis yang merangsang hipofise posterior untuk mengeluarkan oksitosin (Hamranani, 2010). Pijat Oksitosin memiliki beberapa manfaat. manfaat pijat oksitosin antara lain; merangsang pelepasan hormon oksitosin, mempertahankan produksi ASI meskipun ketika ibu dan bayi sakit, mengurangi terjadinya sumbatan ASI, mengurangi bengkak payudara (engorgement), dan memperlancar proses involusi uterus.

Berdasarkan hasil analisis pengetahuan menunjukan bahwa secara keseluruhan terjadi peningkatan pengetahuan pada 25 orang peserta setelah mengikuti pelatihan, dengan rata-rata peningkatan sebesar 13. Hasil p-value 0.000 artinya bahwa secara statistik terdapat pengaruh yang signifikan terhadap peningkatan pengetahuan para pendamping ibu nifas sesudah mengikuti pelatihan pijat oksitosin. Para pendamping ibu nifas memahami bahwa salah satu teknik menstimulasi produksi ASI yang dapat digunakan adalah pijat oksitosin.

Hal ini sesuai dengan penelitian yang dilakukan oleh Hanifah dan Hidayati (2019) yang berjudul pendidikan dan pelatihan kesehatan metode pijat endorphine dan oksitosin pada pembimbing ibu meneteki (Buteki) dalam upaya peningkatan produksi ASI menunjukkan bahwa terdapat peningkatan motivasi ibu menyusui untuk memberikan ASI secara eksklusif kepada bayinya. Para pembimbing Buteki yang telah memperoleh pendidikan dan pelatihan dengan giat memberikan support dan membimbing para ibu meneteki (Buteki) dalam proses menyusui selama kurang lebih 6 bulan. Penelitian Sumiaty dan Anna (2013) menunjukkan bahwa Ibu yang dipijat oksitosin sejak hari pertama sampai hari ketiga memiliki peluang 8,45 kali memiliki produksi ASI lancar dibandingkan dengan ibu yang tidak dipijat oksitosin $(\mathrm{OR}=8,45)$. Sehingga dapat disimpulkan bahwa pijat oksitosin efektif dalam meningkatkan produksi air susu ibu post partum. Maka apabila teknik pijat oksitosin ini dapat dilakukan sedini mungkin pada ibu post partum maka masalah menyusui yang terjadi pada hari pertama kelahiran seperti ASI tidak lancar atau ASI belum keluar dapat diatasi dengan cepat, sehingga ibu post partum tidak dengan mudah untuk memutuskan memberikan susu formula pada bayinya karena masalah tersebut.

Memberikan pelatihan kepada para pendamping ibu nifas merupakan bagian upaya yang dapat dilakukan oleh para petugas kesehatan dalam membantu kliennya untuk memilih dan atau memutuskan perawatan kesehatan masa nifas sesuai kebutuhan klien. Selain itu juga dapat membuat klien merasa lebih puas, karena penyampaian informasi tentang ASI Eksklusif diperoleh langsung oleh orang terdekatnya yang ia percayai. Sehingga upaya ini akan mempengaruhi interaksi antara petugas kesehatan dan klien dalam peningkatan hubungan kepercayaan yang sudah ada. Hal ini didukung oleh teori yang diaparkan oleh Notoatmodjo (2010), bahwa faktor - faktor yang mempengaruhi terbentuknya perilaku manusia dibedakan menjadi 2, yaitu faktor intern dan faktor ekstern. Faktor intern mencakup: motivasi, pengetahuan, kecerdasan, persepsi, dan emosi yang berfungsi untuk mengolah rangsangan dari luar. Sedangkan faktor ekstern meliputi lingkungan sekitar, baik fisik maupun non-fisik seperti: iklim, manusia, sosial ekonomi, dan kebudayaan. 


\section{Keberhasilan.}

Suksesnya kegiatan pelatihan yang dihadiri oleh 25 pendamping ibu nifas (keluarga dan kader) menjadi salah satu ukuran keberhasilan dari kegiatan pengabdian masyarakat ini. Para peserta sangat berpartisipasi aktif selama proses kegiatan dengan melakukan semua tahapan metode pembelajaran dengan baik. Terjadinya peningkatan pengetahuan mengenai ASI Eksklusif dan kemampuan mempraktikkan pijat oksitosin diukur dengan hasil postest yang hampir keseluruhan peserta dapat menjawab dan mendemostrasikan secara benar dan tepat.

Pelatihan kepada pendamping ibu nifas dapat menjadi salah satu alternatif upaya terbentuknya perilaku dalam memotivasi kesadaran ibu nifas untuk memberikan ASI Eksklusif. Edukasi dalam bentuk pelatihan merupakan aspek yang penting dalam pelayanan kesehatan reproduksi, khususnya perawatan kesehatan selama masa nifas. Para petugas kesehatan akan terbantukan oleh aktifitas yang dilakukan oleh para pendamping ibu nifas, karena kontrol perawatan masa nifas selama 24 jam akan lebih efektif dilakukan oleh pendamping ibu nifas seperti suami, keluarga atau kader, sebab merekalah orang terdekat ibu nifas di rumah.

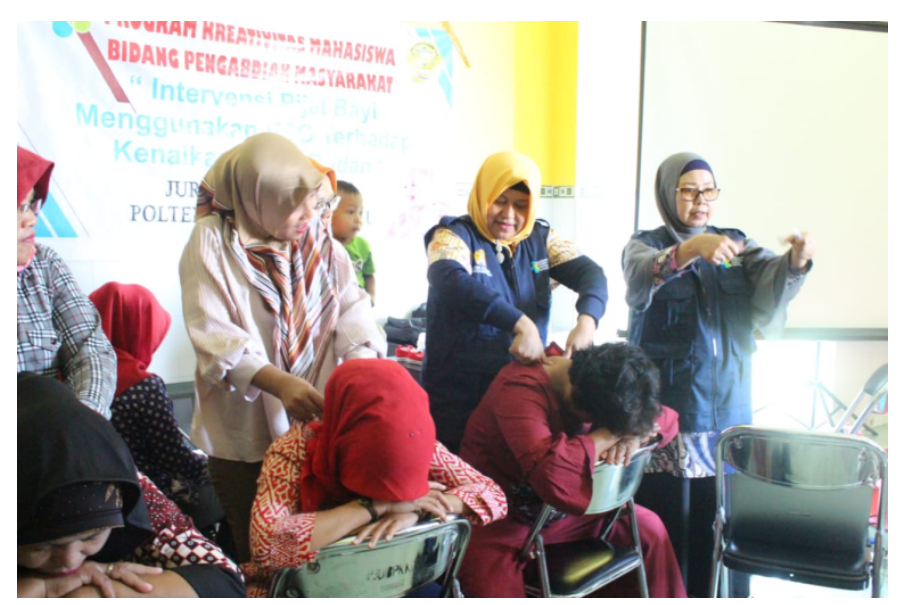

Gambar 4. Foto Praktik Pijat Oksitosin pada ibu nifas di kelurahan Kayumalue Ngapa

\section{KESIMPULAN DAN SARAN}

Kesimpulan pada pengabdian masyarakat ini yaitu terjadinya perubahan berupa peningkatan pengetahuan para pendamping ibu nifas sejumlah 25 orang mengenai ASI Eksklusif dan peningkatan keterampilan melakukan pijat oksitosin. Secara keseluruhan para pendamping ibu nifas mengalami peningkatan pengetahuan setelah mengikuti pelatihan.

Maka disarankan agar petugas kesehatan perlu konsisten dan kontinue memberikan pelatihan kepada para pendamping ibu nifas (suami, keluarga atau kader) agar dapat membantu proses perubahan perilaku pada ibu nifas untuk memberikan ASI secara Eksklusif dan melakukan perawatan selama masa nifas.

\section{UCAPAN TERIMA KASIH}

Penulis mengucapkan terima kasih kepada pihak-pihak yang telah membantu dan mendukung kegiatan pengabdian masyarakat ini yaitu Direktur Poltekkes Kemenkes Palu, Kepala BNPT Kota Palu, Kepala Puskesmas Tawaeli, Bidan Poskesdes Kayumalue Ngapa, para pendamping ibu nifas (keluarga dan kader posyandu) serta ketiga mahasiswa yang terlibat yaitu Desi Oktaviani, Rafika Nur Indasari dan Jihan Oktaviani Tawil. 


\section{DAFTAR PUSTAKA}

Colin, W.B., \& Scott, J.A. (2002). Breastfeeding:reasons for starting, reasons for stopping and problems along the way Australia: School of Public Health.

Cox, S. 2006. Breastfeeding with confidence:Panduan untuk Belajar Menyusui dengan Percaya Diri. Jakarta. Gramedia.

Desmawati. 2008. Efektifitas kombinasi areolla massage dengan rolling massage terhadap pengeluaran ASI secara dini pada ibu post partum di Puskesmas Pamulang dan Cikupa Banten. FIK UI Depok. Jakarta.

Dinkes Prop. Sulteng. 2018. Profil Kesehatan Provinsi Sulawesi Tengah Tahun 2018. Palu. UPT Surveilans, Data \& Informasi Dinkes Prop.Sulteng.

Hamranani, S. 2010. Pengaruh Pijat Oksitosin terhadap Involusi Uterus pada ibu Post Partum yang mengalami persalinan lama di Rumah Sakit Wilayah Kabupaten Klaten.

Hanifah, I dan Hidayati, T. 2019. Pendidikan dan Pelatihan Kesehatan Metode Pijat Endorphine dan Oksitosin Pada Pendamping Buteki dalam Upaya Peningkatan Produksi ASI. Jurnal Paradharma, Vol. 2 (2), pp. 99-102.

Notoatmodjo, S. 2010. Ilmu Perilaku Kesehatan. Jakarta: Rineka Cipta.

Pace, B. 2001. Breastfeeding. The Journal of the American Medical Association.

Roesli, U. 2005. Mengenal ASI Eksklusif. Jakarta: Trubus Agriwidya.

Roesli, U., \& Yohmi, E. 2009. Manajemen Laktasi. Jakarta: IDAI.

Siregar, A. 2004. Pemberian ASI Eksklusif dan Faktor-faktor yang Mempengaruhinya. Medan: FKM USU.

Sumiaty dan Anna, V.P. 2013. Efektivitas Pijat Oksitosin terhadap Ibu Postpartum di RSU Anutapura Palu. Poltekita: Jurnal Ilmu Kesehatan, Vol. II (15), pp. 679-749.

Suradi, R., \& Tobing. 2004. Bahan Bacaan Manajemen Laktasi. Jakarta. Perinasia. WHO \& FAO. 2002. Global Strategy For Infant and Young Child Feeding. Geneva. WHO. 